\title{
GENASIS Information System: A Global Environmental Assessment of Persistent Organic Pollutants
}

\author{
Ivan Holoubek ${ }^{1}$, Ladislav Dušek ${ }^{1,2}$, Jana Klánová ${ }^{1}$, Miroslav Kubásek ${ }^{2}$, \\ Jiř́i Jarkovskýn ${ }^{2}$, Roman Baroš ${ }^{1}$, Klára Komprdová ${ }^{1}$, Zdeňka Bednářová ${ }^{1}$, \\ Richard Hůlek ${ }^{2}$, and Jiří Hřebíček ${ }^{2}$ \\ ${ }^{1}$ Research Centre for Toxic Compounds in the Environment, Masaryk University, \\ Kamenice 126/3, 62500 Brno, Czech Republic \\ ${ }^{2}$ Institute for Biostatistics and Analyses, Masaryk University, Kamenice 126/3, \\ 62500 Brno, Czech Republic
}

\begin{abstract}
Global ENvironmental ASsessment and Information System (GENASIS) is a tool developed by expert teams of the Research Centre for Toxic Compounds in the Environment (RECETOX) and the Institute for Biostatistics and Analyses (IBA) of the Masaryk University in Brno. The aim of GENASIS is to compile validated data on persistent organic pollutants, including their properties, sources, long-term levels, life times, transport mechanisms, effects and risks, scattered throughout various institutions and ministries, and to provide tools for their visualization, analyses, interpretation, assessment of environmental and human risks or modelling of fate. Such a tool should significantly enhance comprehensive understanding of the fate of POPs in the environment, their impacts on ecosystem and the human population.
\end{abstract}

\section{Introduction}

Supporting the sustainable development and management of natural environment means among others prevention of risks and stresses connected to the global changes of climate and pollution. Protection of the environment and biodiversity, as well as prevention of environmentally induced diseases requires implementation of the international measures based on the comprehensive analysis of global trends in environmental as well as epidemiological data.

\section{Background}

Although protection of the environment and human health is an objective of several international conventions on toxic chemicals and wastes (namely Stockholm, Basel, and Rotterdam Conventions), the concept of evaluation of effectiveness of their measures have been developed only recently. Global monitoring plan (GMP) as one of the effectiveness evaluation mechanisms under the Stockholm Convention (SC) was designed to addresses the trends in ambient air and human milk levels of persistent organic pollutants and invited the countries to establish the long-term monitoring 
programmes. Mechanism of evaluation of data collected under the GMP, however, has not been developed yet.

Lack of widely applicable and publicly available environmental databases was identified as a problem also in the SWOT analyses on the national (strategic documents as Long-term directions in research and development in the Czech Republic) as well as European (reports of thematic working group on Environmental sciences of the European Strategic Forum on Research Infrastructures) levels.

\section{Initiation of the GENASIS Project}

The decisions adopted by the Conferences of the Parties to the Basel, Rotterdam and Stockholm Conventions on enhancing cooperation and coordination among the three conventions (the so-called synergies decisions) invited Parties to coordinate their efforts when implementing the three conventions to ensure close cooperation among relevant ministries and programmes at the national levels. The Research centre for toxic compounds in the environment (RECETOX) together with the Institute for biostatistics and analyses (IBA) answered this call by activating the GENASIS project (www.genasis.cz).

As recommended by the synergies decisions, the GENASIS system provides a national information database available to experts as well as to the general public, useful for preparation of national positions for meetings of the conferences of the Parties and other bodies of the Basel, Rotterdam and Stockholm Conventions, but also for the development of regional policies and measures protecting human health and the environment from the harmful impacts or adverse effects of hazardous chemicals and wastes.

\section{Information Database}

The GENASIS system is built as a modular structure providing complex services to a wide range of potential users. The initial version of the database launched in 2010 contains data from the long-term integrated monitoring at the Košetice observatory which is a part of the European Monitoring and Evaluation Programme (EMEP) [1-2], and long-term data from the ambient air MOnitoring NETworks (MONET) in the Czech Republic, Central and Eastern Europe, Africa, Central Asia and Pacific Islands [3-7]. All available data are stored in the intranet database linked to an ArcGIS server enabling spatial interpretation of all results. The user has an access to the maps of the sampling sites, their description, as well as to the POPs concentration values at all sites. Descriptive summary statistics and basic analyses of time series (seasonal and long-term patterns, robust trend estimates) is also available for selected data.

Data from the large-scale monitoring of soil, sediment, and surface water [8-9] will be included in a new version the GENASIS system, which is currently under development and will be launched in 2011. Enhanced analytical tools allowing implementation of algorithms for spatial analyses, and modules enabling comparative analyses of multiple substances or matrices will be also introduced [10-11]. Based on the contract signed between RECETOX and the Czech Ministry of Environment, an import 
of data from external sources will also be initiated in 2011. Compatibility of the GENASIS system with existing databases is crucial in order to assess the environmental patterns, calibrate the indicator systems, and implement the legislation requirements. The fully developed system will serve as an interactive, on-line national POPs inventory of the Czech Republic.
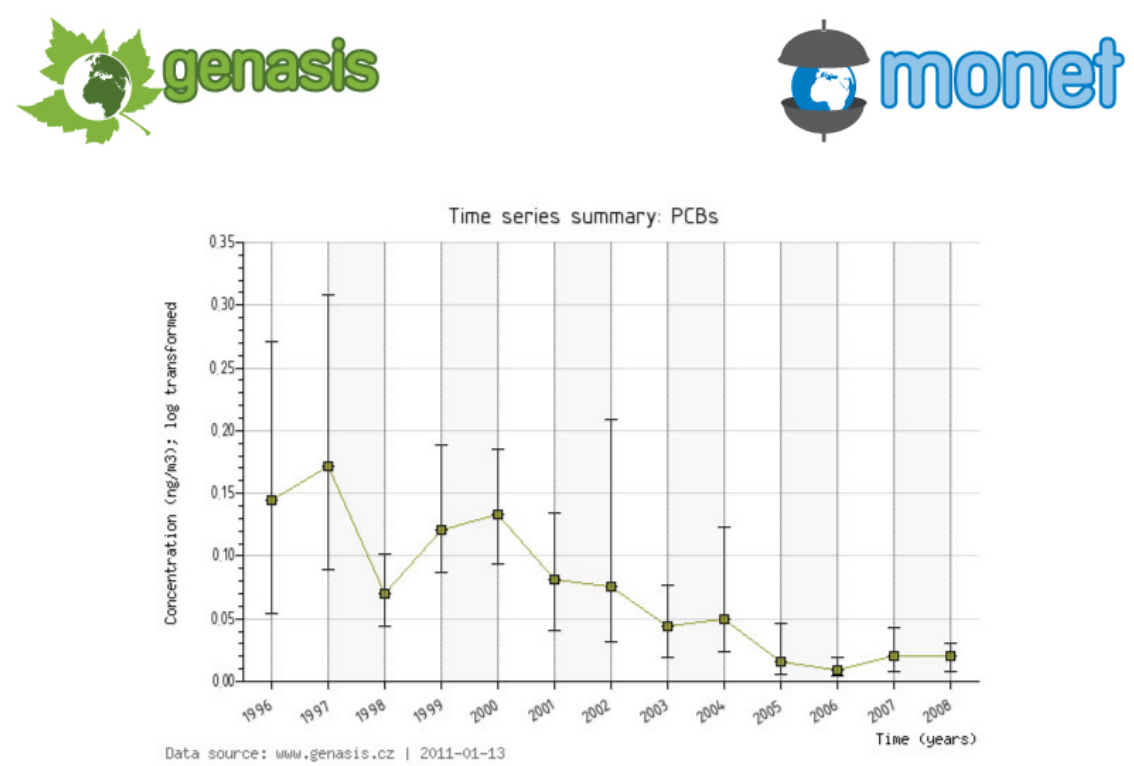

Fig. 1. Temporal trend in PCBs concentration in active air sampling at Košetice station (median and 5-95th percentile; 1996-2008)

\section{Analytical and Interpretation Tools}

Development of the information system includes accumulation of environmental data from various sources, their validation, followed by the advanced data analyses, interpretation, visualization, and spatial presentation supported by the geographic information systems (GIS).

Available interpretation tools include the POPspedia database providing information on chemicals of interest, detailed description of the sampling sites and sampling techniques, summary description of contamination, analyses of the time series and seasonal variability, comparison of sites, regions, time periods, and analytes, correlation analysis, and model calculators.

E-learning modules focused on the assessment of ecological risks provide the additional support to variety of users. A methodology of the ecological risk assessment starts with the problem formulation, continues with the assessments of exposure, effects, and risks, and is completed by the risk communication and management 


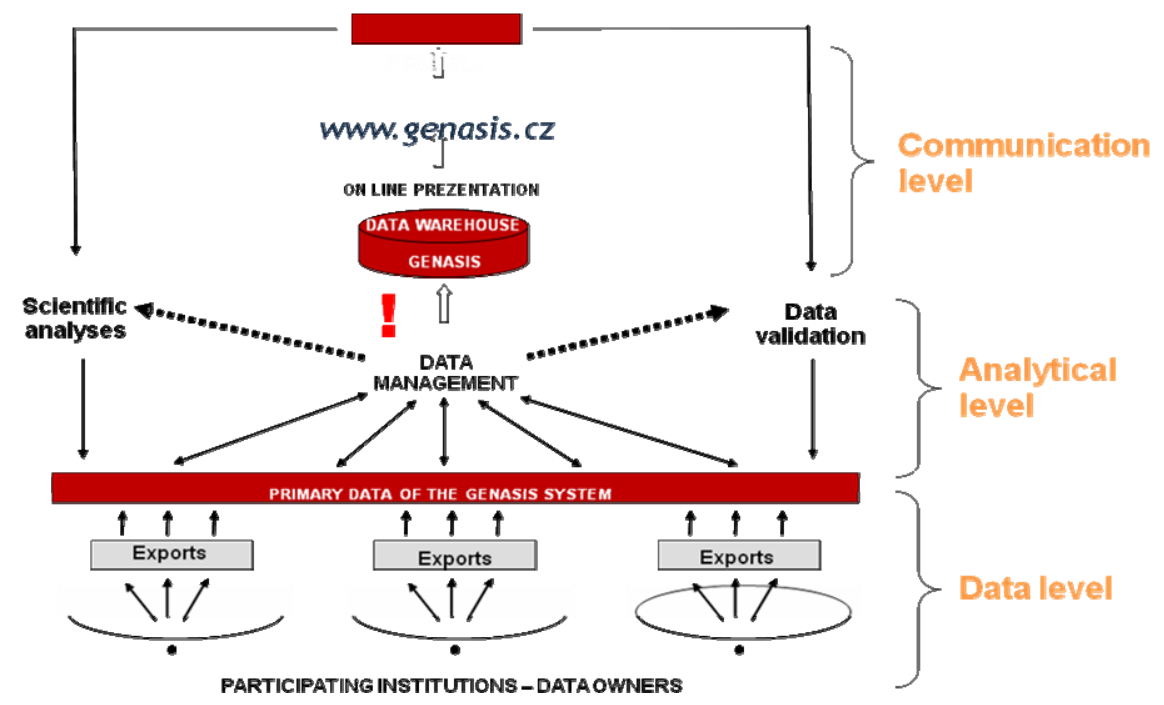

Fig. 2. GENASIS system architecture

\section{Deliverables and Impacts of the GENASIS Project}

RECETOX acting as the National POPs Centre of the Czech Republic became a documentation centre gathering available national information on environmental risks and impacts on human health relevant to the three conventions. However, in the role of the SC Regional Centre, RECETOX also offers GENASIS as a global system for information exchange and a clearing-house mechanism for all three conventions. Such a system is very valuable for the evaluation of the effectiveness of the Stockholm Convention measures. Currently, GENASIS hosts all available data from the international MONET project monitoring POPs in ambient air of Europe, Africa, Asia and Pacific.

The international dimension of both, the MONET and GENASIS programmes, provides an opportunity for strengthening technical assistance and capacity building in the field of data collection, interpretation and visualization on the regional and global levels. Special attention is being paid to the needs of developing countries and countries with economies in transition.

By providing access to necessary information, the GENASIS system supports decision-making on the sound management of chemicals throughout their life cycles as well as the sound management of hazardous wastes. It is also an important tool for the development of policies and measures protecting the environment and human health, and supporting sustainable development.

Last but not least, it is a tool for the joint outreach and enhancement of public awareness as an important means of prevention and environmental protection. As such, the GENASIS provided a model of coordination mechanism and example of good coordination practice, and it was selected for publication in the book of Synergies success stories jointly prepared by the Division for Sustainable Development, United Nations Department of Economic and Social Affairs (UNDESA), and Secretariats of the Stockholm, Basel, and Rotterdam Conventions in 2011. 


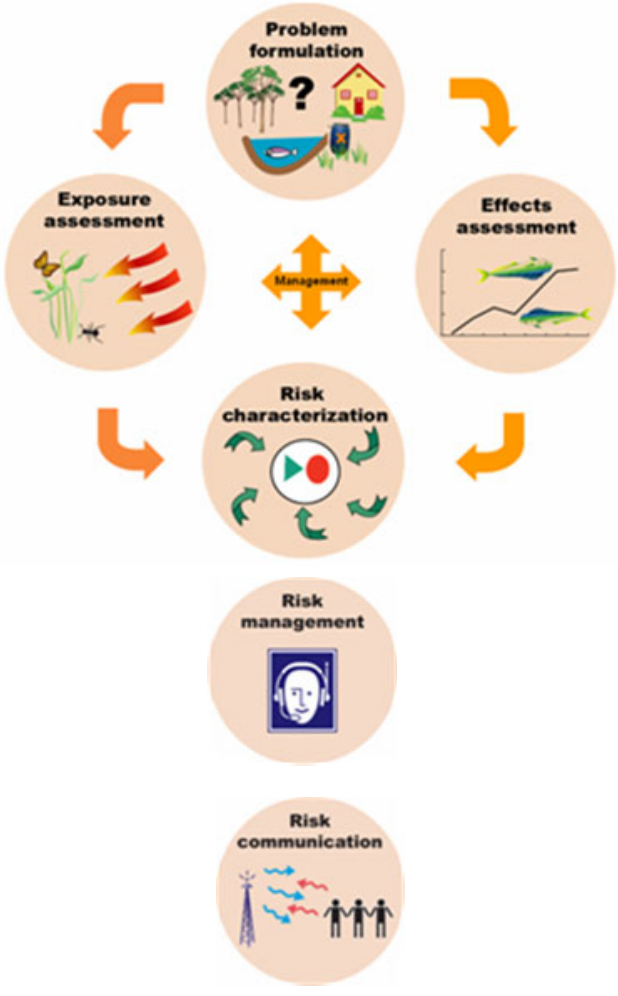

Fig. 3. A scheme of the e-learning module focused on ecological risk assessment

Acknowledgments. Development of the GENASIS system is supported by the CETOCOEN project (CZ.1.05/2.1.00/01.0001) of the European Structural Funds, and the INCHEMBIOL project (MSM 0021622412) of the Ministry of Education of the Czech Republic.

\section{References}

1. Holoubek, I., Klánová, J., Jarkovský, J., Kohoutek, J.: Trends in background levels of persistent organic pollutants at Kosetice observatory, Czech Republic. Part I. Ambient air and wet deposition 1988-2005. J. Environ. Monit. 9(6), 557-563 (2007)

2. Dvorska, A., Lammel, G., Klanova, J., Holoubek, I.: Košetice, Czech Republic - ten years of air pollution monitoring and four years of evaluating the origin of persistent organic pollutants. Environ. Pollut. 156(2), 403-408 (2008)

3. Harner, T., Bartkow, M., Holoubek, I., Klanova, J., Sweetman, A.J., Wania, F., Jones, K.C.: Passive air sampling for persistent organic pollutants: introductory remarks to the Special Issue. Environ. Pollut. 144(2), 361-364 (2006)

4. Klánová, J., Kohoutek, J., Hamplová, L., Urbanová, P., Holoubek, I.: Passive air sampler as a tool for long-term air pollution monitoring: Part 1. Performance assessment for seasonal and spatial variations. Environmental Pollution 144(2), 393-405 (2006) 
5. Čupr, P., Klánová, J., Bartoš, T., Flégrová, Z., Kohoutek, J., Holoubek, I.: Passive air sampler as a tool for long-term air pollution monitoring: Part 2. Air genotoxic potency screening assessment. Environ. Pollut. 144(2), 406-413 (2006)

6. Klánová, J., Čupr, P., Holoubek, I., Borůvková, J., Kareš, R., Tomšej, T., Ocelka, T.: Monitoring of persistent organic pollutants in Africa. Part 1: Passive air sampling across the continent in 2008. J. Environ. Monit. 11, 1952-1963 (2009)

7. Klánová, J., Čupr, P., Kohoutek, J., Harner, T.: Assessing meteorological parameters on the performance of PUF disks passive air samplers for POPs. Environ. Sci. Technol. 42(2), $550-555$ (2008)

8. Holoubek, I., Klánová, J., Jarkovský, J., Kubík, V., Helešic, J.: Trends in background levels of persistent organic pollutants at Kosetice observatory, Czech Republic. Part II. Aquatic and terrestric environments 1988-2005. J. Environ. Monit. 9(6), 564-571 (2007)

9. Růžičková, P., Klánová, J., Čupr, P., Lammel, G., Holoubek, I.: An assessment of air-soil exchange of polychlorinated biphenyls and organochlorine pesticides across Central and Southern Europe. Environ. Sci. Technol. 42(1), 179-185 (2008)

10. Komprda, J., Kubošová, K., Dvorská, A., Scheringer, M., Klánová, J., Holoubek, I.: Application of an unsteady state environmental distribution model to a decadal time series of PAH concentrations in the Central Europe. J. Environ. Monit. 11, 269-276 (2009)

11. Kubošová, K., Komprda, J., Jarkovský, J., Sánka, M., Hájek, O., Dušek, L., Holoubek, I., Klánová, J.: Spatially resolved distribution models of POP concentrations in soil: A stochastic approach using regression trees. Environ. Sci. Technol. 43(24), 9230-9236 (2009) 